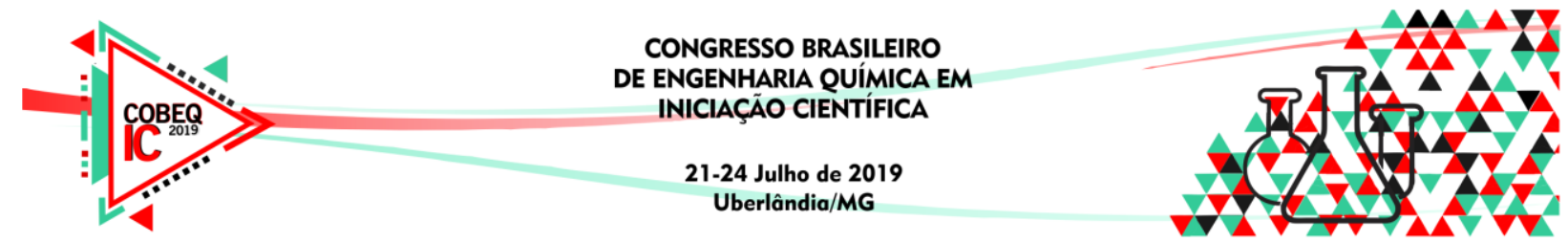

\title{
AVALIAÇÃO DO TEMPO DE FERMENTAÇÃO PARA PRODUÇÃO DE CERVEJA ARTESANAL DE UM EMPRESA CERVEJEIRA DA CIDADE DE MOSSORÓ - RN.
}

\author{
D. C. S. SOUZA ${ }^{1}$, T. F. SILVA ${ }^{1}$, V. C. MEDEIROS ${ }^{1}$, M. E. A. SANTANA ${ }^{1}$ e A. D. T. \\ PINHEIRO $^{1}$ \\ ${ }^{1}$ Universidade Federal Rural do Semi-Árido, Faculdade de Engenharia Química \\ E-mail para contato: darliannesouza91@outlook.com
}

\begin{abstract}
RESUMO - A cerveja artesanal se diferencia em diversos aspectos da cerveja industrial. Também chamada de cerveja gourmet, pode-se afirmar que a maior distinção entre elas é o processo de fabricação, além de apresentar diferenças significativas na estética, valor de mercado e escala de produção. A cerveja artesanal é feita com ingredientes selecionados com o propósito de serem obtidos aromas e sabores únicos. Um fator de grande importância em processos de fermentação alcoólica é o comportamento do microrganismo e suas rotas metabólicas bem como o perfil cinético. Este trabalho teve como principal objetivo a avaliação do tempo do processo de fermentação de uma empresa de cerveja artesanal. Para tanto, foi realizado um estudo do processo de fermentação de uma cerveja artesanal do tipo Ale puro malte e a construção da curva de crescimento da levedura Saccharomyces cerevisiae através de analises diretas como a contagem de placas que pode apresentar valores de células viáveis e também observar a concentração de células da levedura através de método indireto. Observou-se as fases de crescimento da levedura (Lag, exponencial, estacionária e morte) após 7 dias de fermentação característica desta levedura e foi obtido valor de velocidade especifica de crescimento máximo de $0,034 \mathrm{~h}^{-1}$.
\end{abstract}

Palavras-chave: Cerveja Artesanal, Otimização, Fermentação, Saccharomyces cerevisiae.

\section{INTRODUÇÃO}

A bebida carbonada com baixo teor alcoólico conhecida como cerveja, provém de uma fermentação alcoólica ocasionada pelo processo metabólico de microrganismos. As leveduras das espécies Saccharomyces cerevisiae (utilizada na produção de cerveja tipo Ale) e Saccharomyces uvarum (utilizada na produção de cerveja tipo Lager), são de grande importância na produção de cerveja, sendo elas amplamente comercializadas e utilizadas para fins similares, como podemos observar no trabalho de PALMER (2006). Com base em Amorin (1982), por sua capacidade fermentativa e por apresentar processo bioquímico bastante conhecido, as leveduras são o grupo de microrganismos mais comercialmente explorados.

De acordo com De Keukelerie (2000), a cerveja é uma bebida elaborada com malte de cevada, água, lúpulo e fermento. Em países, como por exemplo a Alemanha, somente a 


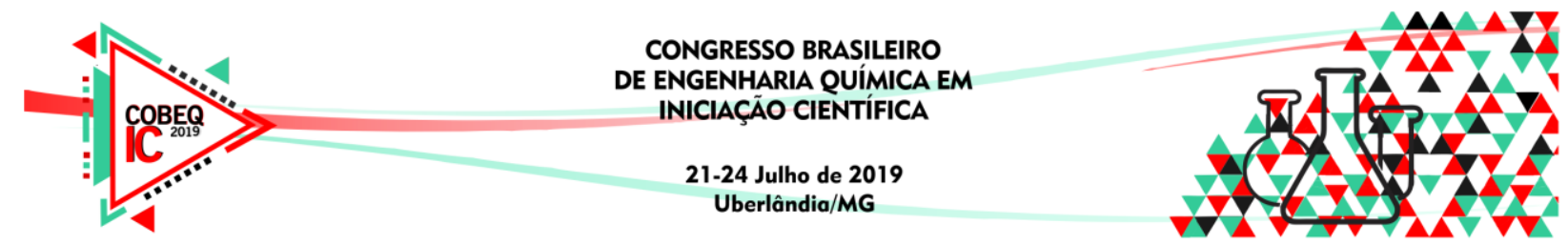

cevada é empregada na obtenção do malte, porém, na maioria dos outros países que produzem cerveja, é comum a utilização de outros constituintes para compor o malte, por exemplo, o arroz e o milho. Segundo Schidell (2001), um aspecto relevante no estudo cinético microbiológico é a representação gráfica de uma população microbiana, que se refere ao crescimento de culturas de bactérias, de fungos ou quaisquer outros microrganismos. Sendo de fundamental importância o acompanhamento da cinética de crescimento do microrganismo tendo em vista que a formação do produto que muitas vezes é objeto de interesse, está diretamente ligado ao crescimento e concentração celular.

No processo de fermentação, podemos analisar valores de concentração de um ou mais componentes em função do tempo de uma dada cultura através de um estudo cinético, segundo os trabalhos de Pinto e Oliveira (2015, 2011). Um aspecto relevante no estudo cinético microbiológico é a representação gráfica de uma população microbiana, que se refere ao crescimento de culturas de bactérias, de fungos ou quaisquer outros microrganismos. Sendo de fundamental importância o acompanhamento da cinética de crescimento do microrganismo tendo em vista que a formação do produto que muitas vezes é objeto de interesse, está diretamente ligado ao crescimento e concentração celular, com base em Lima (2001). É importante ressaltar que o crescimento microbiano se refere ao aumento do número de células. A quantificação de microrganismo pode ser feita por métodos diretos através da contagem de colônias ou por métodos indiretos, pela medida de sua atividade metabólica, como podemos ver em Alves (1996)

Alguns microrganismos quando inoculados em meio líquido de crescimento e a população são submetidas a contagens dentro de intervalos regulares é possível construir um gráfico que represente uma curva de crescimento microbiano, em que podemos observar as fases, lag, log, estacionária e de morte, segundo Tortora (2010):

\section{OBJETIVOS}

Avaliar possível otimização do tempo de fermentação do processo produtivo de uma cerveja artesanal produzida por uma empresa cervejeira.

\section{MATERIAIS E MÉTODOS}

Para a realização deste trabalho, utilizou-se como material de estudo uma cerveja artesanal do tipo Blonde Ale. A cerveja, denominada Ibaté, foi cedida pela empresa Bacurim de cerveja artesanal. Foram realizadas análises para estimar o crescimento de microrganismos através de métodos diretos e indiretos. Realizou-se análises de espectrofotometria em períodos pré-estabelecidos com a finalidade de obter valores de absorbância das amostras. Utilizou-se a contagem do número de células viáveis por contagem em placas com a finalidade quantificar a levedura ao decorrer de 7 dias de fermentação.

\subsection{Meio de Cultura}




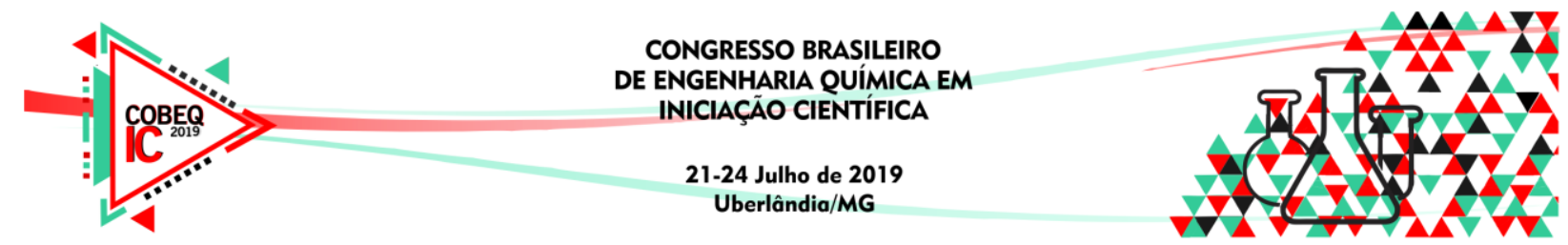

A princípio foi realizado o preparo do meio de cultura das células de levedura, empregando o meio líquido YEPD. Para um volume de $1400 \mathrm{~mL}$, pesou-se $14 \mathrm{~g}$ de extrato de levedura, 28g de Peptona, 42g de Glicose e 30,3g de Ágar. $\mathrm{O}$ pH foi ajustado para 4,5, valor que está dentro da faixa considerada ideal para fermentação de cerveja. O material utilizado foi esterilizado em autoclave numa temperatura de $121^{\circ} \mathrm{C}$ por 15 minutos.

\subsection{Análise do pH}

Com base com Galvão (2017), o pH pode indicar se o mosto apresenta condições favoráveis para o desenvolvimento das leveduras para a fermentação. Para a produção de cerveja artesanal, o controle desse fator é de extrema importância, tendo em vista que o pH deve apresentar pouca variação na fabricação desta bebida, apresentando sempre um caráter mais ácido. Durantes os sete dias de fermentação foi observado a variação do mesmo de forma rigorosa em todos os horários que foram feitas coletas das amostras para análise.

\subsection{Espectrofotometria}

A absorbância foi medida com a ajuda de um espectrofotômetro, sendo as amostras tiradas periodicamente e seus valores utilizados para analisar as fases de crescimento da levedura utilizada na fermentação, utilizando um comprimento de onda de $250 \mathrm{~nm}$.

\subsection{Plaqueamento}

Em ambas as fermentações, foram utilizadas uma solução contendo $1 \mathrm{~mL}$ da solução mãe (mosto contendo levedura) $+9 \mathrm{~mL}$ de solução salina $(\mathrm{NaCl} 0,9 \%)$ em placas de petri contendo o meio YEPD. O plaqueamento foi feito em triplicata para as seguintes diluições: $10^{-1}, 10^{-2}$ e $10^{-3}$. A partir destes da observação das diferentes diluições foi possível observar qual delas apresenta uma melhor visualização de células. Através desse método, foi feito a contagem de unidades formadora de colônias (UFC por $\mathrm{mL}$ de meio), a afim de estimar quantitativamente células viáveis.

\subsection{Contagem de Células Viáveis}

Segundo Madigan (2010), a quantificação de uma população microbiana é medida pelo analise das alterações no número de células. A partir da observação e enumeração das células presentes pode ser feita uma contagem total do número de microrganismos presentes em uma cultura ou em uma amostra.

\section{RESULTADOS E DISCUSSÃO}

Inicialmente obteve-se uma curva de calibração para relacionar a absorbância (nm) com a concentração de célula (g/L) então avaliou-se o comportamento do crescimento celular em função do tempo. $O$ resultado da contagem de células totais expressa em termos da concentração celular $\left(\mathrm{g} \cdot \mathrm{L}^{-1}\right)$. 


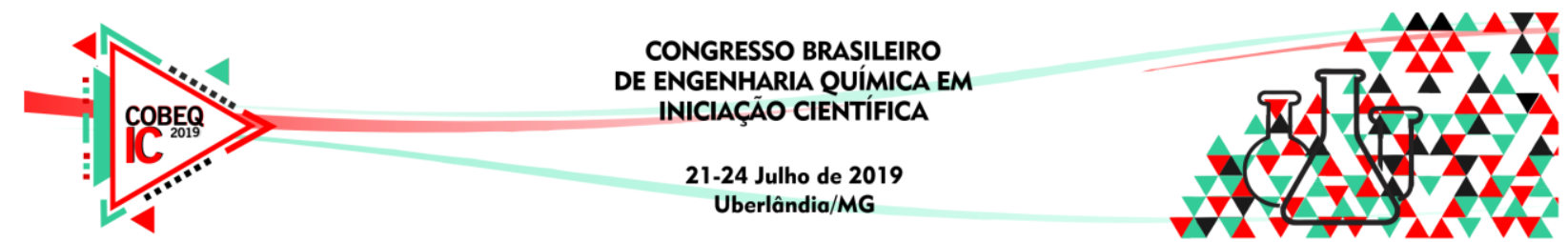

O valor de máxima velocidade específica de crescimento celular, $\mu_{\text {máx }}$, pode ser obtido a partir do balanço de massa para a célula, descrito na Equação 1.

$$
\frac{d x}{d t}=\mu_{x} \times X
$$

Sabendo que na fase exponencial $\mu_{\mathrm{x}}$ é igual a $\mu_{\text {máx }}$, a Equação 1 pode ser integrada, dando origem a Equação 2.

$$
\ln \left(\frac{x}{x_{0}}\right)=\mu_{\max } \times t
$$

A partir da regressão linear dos dados experimentais na fase exponencial, o valor de $\mu_{\text {máx }}$ para a célula foi de $0,034 \mathrm{~h}^{-1}$, sendo este um valor baixo para o crescimento celular.

A quantificação de células viáveis pode ser feita através de contagem de placa, sendo o resultado apresentado na Figura 2.

Figura 1 - UFC/mL em função do tempo.

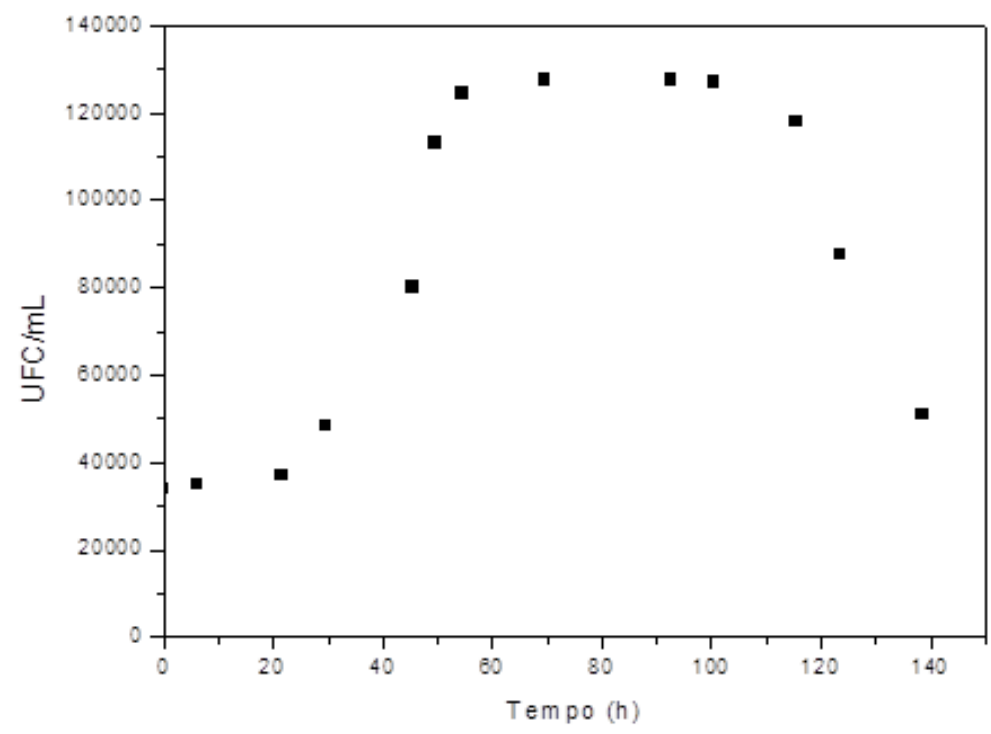

Observa-se uma fase lag de aproximadamente $24 \mathrm{~h}$, seguida por uma fase exponencial que se inicia no segundo dia de fermentação. A fase estacionária inicia entre 60 e 100 horas, enquanto a fase de morte do microrganismo ocorre após 100 horas de fermentação.

\section{CONCLUSÃO}

Por meio da construção da curva de crescimento celular foi possível observar as fases de crescimento e quanto tempo o microrganismo se mantem em cada fase. A partir desses 


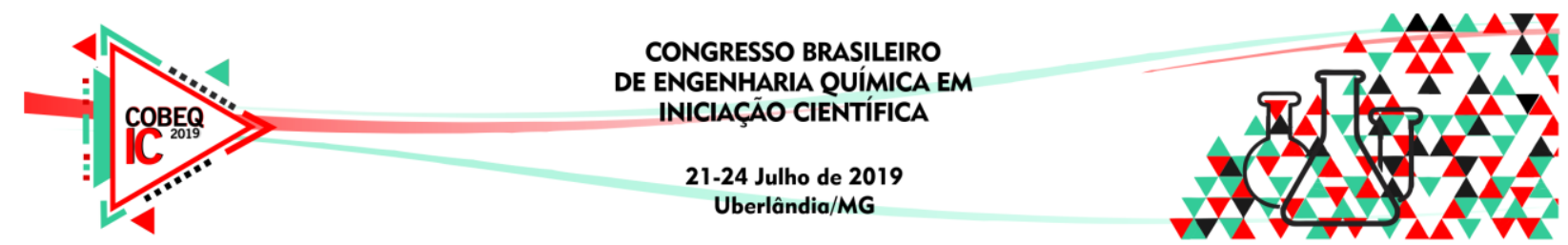

dados podemos constatar que é possível a otimização em função do tempo de fermentação da cerveja.

\section{REFERENCIAS}

ALVES, J. G. L. F. Estudo da Influência da Temperatura na Cinética de Crescimento Anaeróbico de Saccharomyces cerevisiae. Tese (Mestrado em Engenharia de Alimentos). Universidade estadual de Campinas. São Paulo, 1996.

AMORIN, H. V; OLIVEIRA, A. J. Infecção na fermentação: Como evita-la. STAB Álcool e Açúcar, Piracicaba, v.2, n.5, 1982.

DE KEUKELERIE, D. Fundamentals of beer and hop chemistry. Química Nova, n. 23, p. 108-112, 2000.

GALVÃO, Manuel Pereira. A Química da cerveja. Química, Via longa, p.6-12, 1997. Disponível em: <http://www.spq.pt/magazines/BSPQ/589/article/3000790/pdf>. Acesso em: 26 de agosto de 2017.

LIMA, U. A., BASSO, L. C. e AMORIM, H. V. Fadiga. In: Biotecnologia industrial: Processos fermentativos e enzimáticos. São Paulo-SP. Edgard Blucher, v.3, p. 1-43, 2001.

MADIGAN, M.T.; MARTINKO, J.M.; DUNLAP, P.V.; CLARK, D.P. Microbiologia de Brock. 12. ed., Porto Alegre: Artmed, 2010. 1160 p.

OLIVEIRA, M. E. S. Elaboração de bebida alcoólica fermentada de Cagaita (Eugenia dysenterica, DC) empregando leveduras livres e imobilizadas. 75f. Dissertação (Mestrado Microbiologia agrícola). Departamento microbiologia, Universidade Federal de Lavras, UFLA. Lavras/MG, 2011.

PALMER, J. How to brew.3. ed. Nova Iorque: Brewer Association, 2006.

PINTO, L. I. F. Acerola (Malpighia emarginata DC) e Abacaxi (Ananas comosus L. Merril) como adjunto no processamento de cerveja: caracterização e aceitabilidade. Fortaleza, 2015. 87f. Dissertação (Mestrado- Ciência e Tecnologia de Alimentos). Departamento de tecnologia de alimentos, Universidade Federal do Ceará - Campus de Fortaleza-Ce.

SCHMIDELL, W.; LIMA, U.A.; AQUARONE, E.; BORZANI, W. Biotecnologia Industrial. São Paulo, Edgard Blücher Ltda, vol.2, 2001.

TORTORA, G.J.; FUNKE, B.R.; CASE, CL. Microbiologia. 10. ed., Porto Alegre: Artmed, 2010. 